\title{
Intensi Kewirausahaan : Studi pada Faktor Individual, Situasional, dan Perbedaan Gender
}

\author{
Audrey Jocelyn Hertanto dan Frangky Slamet \\ Program Studi Manajemen Fakultas Ekonomi \& Bisnis \\ Universitas Tarumanagara \\ E-mail : audrey.115160016@stu.untar.ac.id
}

\begin{abstract}
The purpose of this research is to determine the effect of individual factors and situational factors, as well as gender difference as the moderating variable, on the entrepreneurial intention among vocational high school students in West Jakarta. The number of samples use in this study is50 respondents of vocational high school students in West Jakarta and use purposive sampling technique for choosing the respondents. This research uses Statistical Package for the Social Science (SPSS) software version 17.0 to analyze the data collected. The results of this research indicates that individual factors, situational factors and gender difference have no significant impact on entrepreneurial intention. However, individual factors demonstrate greater effect on entrepreneurial intention than situational factors.
\end{abstract}

Keywords: Entrepreneurial Intention, Individual Factors, Situational Factors, Gender Difference

Abstrak: Penelitian ini bertujuan untuk mengetahui pengaruh faktor individual, situasional terhadap intensi kewirausahaan dengan perbedaan gender sebagai variabel moderasi pada siswa/I SMK di Jakarta Barat. Sampel yang digunakan dalam penelitian ini sebanyak 50 responden yang merupakan siswa/I SMK di daerah Jakarta Barat dan teknik pemilihan sampel yang digunakan adalah purposive sampling. Untuk metode analisis data pada penelitian ini menggunakan softwareStatistical Package for the Social Science (SPSS) versi 17.0. Hasil penelitian ini menunjukkan bahwa faktor individual, faktor situasional, dan perbedaan gender tidak memiliki pengaruh terhadap intensi kewirausahaan. Namun, faktor individual memiliki pengaruh yang lebih kuat daripada faktor situasional terhadap intensi kewirausahaan.

Kata Kunci: Intensi Kewirausahaan, Faktor Individual, Faktor Situasional, Perbedaan Gender

\section{LATAR BELAKANG}

Pengangguran dan kemiskinan masih menjadi masalah utama yang dihadapi Indonesia. Berdasarkan data Badan Pusat Statistik, Tingkat Pengangguran Terbuka (TPT) pada Februari 2019 sebesar 5,01\%, di mana 8,63\% dari besaran TPT tersebut merupakan lulusan Sekolah Menengah Kejuruan (SMK) (www.bps.go.id, Februari 2019). Dengan besaran persentase TPT tersebut, Indonesia menduduki peringkat kedua terbanyak di antara negara-negara ASEAN di bawah Filipina. Untuk kemiskinan, berdasarkan data Badan Pusat Statistik, persentase penduduk miskin pada Maret 2019 sebesar 9,41\% yaitu sebanyak 25,41 juta orang (www.bps.go.id, Juli 2019). 
Dirangkum dari situs berita CNBC Indonesia, salah satu faktor yang mengakibatkan tingginya angka pengangguran di Indonesia adalah jumlah lapangan pekerjaan yang tersedia tidak sebanding jumlah angkatan kerja yang ingin mencari pekerjaan. Masalah tersebut membuat seseorang tidak memiliki penghasilan tetap dan pada akhirnya berdampak pada munculnya kemiskinan (www.cnbcindonesia.com, Agustus 2019). Salah satu alternatif untuk memecahkan masalah pengangguran dan kemiskinan yang terjadi adalah dengan memberdayakan masyarakat melalui penyelenggaraan program kewirausahaan (entrepreneurship), karena pada saat seseorang memiliki jiwa wirausaha maka mereka tidak perlu mengkhawatirkan jumlah lapangan pekerjaan yang sedikit (www.liputan6.com, Maret 2019).

Kewirausahaan merupakan proses mengintegrasikan peluang, sumber daya, dan orang (pelaku usaha) (Timmons dan Spinelli, 2009). Menurut teori sifat kewirausahaan, terdapat sifat tertentu dari dalam individu (faktor individual) yang dapat membentuk niat kewirausahaan (Krueger, 1993). Niat kewirausahaan dapat dilihat dari kecenderungan seorang individu untuk mengambil peluang dalam situasi pengambilan keputusan. Seorang wirausaha memiliki kecenderungan mengambil risiko yang lebih tinggi daripada yang lain (Stewart et al., 1999) karena mereka diyakini lebih mampu menoleransi situasi yang tidak pasti (Stewart dan Roth, 2001).

Selain itu, niat kewirausaahan dapat dipengaruhi oleh keinginan seseorang untuk melakukan kontrol terhadap hasil, penghargaan, keberhasilan atau kegagalan dalam hidup mereka. Hal ini sering disebut dengan locus of control. Seseorang yang memiliki locus of control tinggi percaya bahwa segala hasil dari tindakan dan perilaku mereka bukanlah sebuah keberuntungan, nasib atau kebetulan semata (Rotter, 1966). Oleh karena itu, seseorang dengan locus of control yang tinggi suka mengeksplorasi peluang yang ada dan dapat menciptakan sebuah bisnis baru dari peluang tersebut (Mazzarol et al., 1999).

Niat kewirausahaan juga dipengaruhi oleh kebutuhan akan prestasi. Setiap individu pasti memiliki kemauan yang tinggi untuk berprestasi dalam hidupnya. Orang-orang seperti ini cenderung lebih kompetitif, suka menyelesaikan masalah tanpa bantuan orang lain dan tertarik pada hasil dari upaya mereka sendiri (Sesen, 2013). Mereka yang membutuhkan kebutuhan akan prestasi yang tinggi lebih suka memiliki kendali yang besar atas apa yang akan dihasilkan dan menginginkan umpan balik langsung (McClelland, 1965). Oleh karena itu, kebutuhan akan prestasi yang tinggi perlu dimiliki oleh para calon wirausaha.

Otonomi pekerjaan merupakan salah satu alasan lain bagi seorang individu dalam berwirausaha. Otonomi pekerjaan mencerminkan kebutuhan untuk bebas, menggunakan penilaian sendiri, dan mengambil tanggung jawab pribadi bagi para pelaku wirausaha itu sendiri (Shane et al., 2012). Maka dari itu, tidak sedikit orang yang memilih untuk berwirausaha karena bisa lebih bebas dalam bekerja daripada menjadi karyawan di sebuah perusahaan. Menurut penelitian Walter dan Heinrichs (2015), individu yang memiliki keinginan untuk bebas yang tinggi juga akan memiliki intensi kewirausahaan yang tinggi.

Untuk menjadi wirausaha, seorang individu harus memiliki cara pandang yang berbeda terhadap sebuah permasalahan, mereka harus mampu mengubah permasalahan menjadi sebuah peluang dan berpikir kreatif-inovatif untuk menyelesaikan permasalahan tersebut (www.idntimes.com, Oktober 2018). Dari permasalahan yang muncul, akan timbul tantangan dalam bekerja. Biasanya seseorang yang menyukai tantangan pekerjaan akan lebih termotivasi menjadi seorang wirausaha. Hal ini berdasar karena seorang wirausaha dituntut memiliki sikap yang lebih optimis dan tidak mudah putus asa saat dihadapkan pada situasi ketidakpastian di mana mungkin tidak ada hasil yang jelas (Budner, 1962) dan tidak bisa memprediksi potensi keberhasilan (Schere, 1982), yang sering kali terjadi akibat tantangan pekerjaan tersebut. 
Namun, tidak sedikit pula individu yang masih mencari stabilitas dalam pekerjaannya. Orang-orang seperti ini beranggapan bahwa menjadi wirausaha adalah suatu ketidakpastian, mereka memilih untuk menjadi karyawan di sebuah perusahaan karena keamanan kerja yang terjamin dan memiliki kelanjutan kerja yang nyata (Probst, 2006). Mereka yang memiliki sikap seperti ini akan merasa tidak nyaman atau tidak sesuai jika menjadi seorang wirausaha. Oleh karena itu, individu yang mencari keamanan kerja cenderung memiliki intensi yang rendah untuk berwirausaha.

Niat berwirausaha juga dipengaruhi oleh faktor eksternal (situasional), di mana ada sebuah situasi yang membuat seorang individu menjadi pelaku wirausaha (Delmar dan Davidsson, 2000). Faktor situasional tersebut adalah pendidikan dan lingkungan untuk memulai usaha (Keat et al., 2011). Dalam berwirausaha, pendidikan kewirausahaan penting karena dapat menumbuhkan motivasi seseorang untuk menjadi wirausaha (Gelard dan Saleh, 2010).

Kesadaran akan pentingnya pendidikan kewirausahaan ini harus dimulai sejak dini. Di Indonesia, pemerintah telah mulai menggunakan sekolah-sekolah (khususnya jenjang SMA/MA/SMK) untuk menyadarkan generasi muda akan pentingnya kewirausahaan. Pendidikan kewirausahaan ini bertujuan untuk menciptakan seorang wirausaha yang inovatif dan kreatif. Ketika seorang individu lebih berpengetahuan tentang kewirausahaan melalui pendidikan yang ia dapatkan, maka secara signifikan akan mempengaruhi niat mereka untuk menjadi pengusaha (Linan et al. , 2011).

Faktor situasional kedua yang mempengaruhi niat kewirausahaan adalah lingkungan di mana bisnis akan dibangun. Lingkungan untuk berwirausaha harus menguntungkan bagi perkembangan bisnis baru, misalnya adanya penerapan pinjaman dengan suku bunga rendah, serta kebijakan dan peraturan yang mendukung perkembangan wirausaha; sehingga berwirausaha dianggap sebagai pekerjaan yang menarik dan menumbuhkan niat seseorang untuk berwirausaha (Davidsson dan Henrekson, 2002). Oleh karena itu, niat kewirausahaan dapat diteliti melalui faktor individual dan faktor situasional (Keat et al. , 2011).

Faktor individual dan faktor situasional dalam meneliti niat wirausaha dapat diperkuat dengan perbedaan gender. Bukti empiris menunjukkan bahwa pria memiliki niat kewirausahaan yang lebih tinggi daripada wanita (Díaz-García dan Jiménez-Moreno, 2010). Dari penelitian sebelumnya, pria cenderung memiliki perilaku pengambilan risiko dan efikasi diri yang lebih tinggi daripada wanita, tetapi lebih rendah dalam hal kebutuhan pendidikan kewirausahaan (Wilson et al. , 2007). Namun, ada juga penelitian yang mengungkapkan bahwa tidak adanya perbedaan antara pria dan wanita (Díaz-García dan Jiménez-Moreno, 2010). Oleh karena itu, perbedaan gender yang mempengaruhi faktor individual dan situasional akan diteliti dalam penelitian ini.

Memahami kewirausahaan yang sesungguhnya memungkinkan para pengajar, penasihat, maupun pembuat kebijakan untuk mendapatkan gambaran yang lebih jelas mengenai bagaimana niat terbentuk dan bagaimana keyakinan, persepsi, serta motif calon wirausahawan dapat memengaruhi niatnya untuk memulai bisnis (Wang et al., 2011). Berdasarkan gambaran mengenai permasalahan di atas, timbul ketertarikan untuk membahas lebih dalam mengenai intensi berwirausaha yang dimiliki oleh generasi muda khususnya mereka yang telah mulai ditanamkan mengenai pentingnya kewirausahaan sejak di bangku sekolah. Dalam berwirausaha, intensi memainkan peranan penting karena intensi merupakan langkah awal untuk memulai kewirausahaan itu sendiri. Penelitian ini ingin mengetahui seberapa besar intensi generasi muda saat ini untuk berwirausaha jika dihubungkan dengan faktor situasional, individu, serta perbedaan gender yang ada. 


\section{KAJIAN TEORI}

Theory of Planned Behavior (TPB) adalah dasar teoritis yang dapat memahami hubungan antara sikap, niat, serta perilaku individu (Ajzen, 1991), yang dapat menjadi kerangka dalam memprediksi niat wirausaha dan menunjukkan apakah seorang individu siap untuk menerapkan perilaku kewirausahaan. Berdasarkan TPB, kontrol individu terhadap perilakunya dapat menghasilkan tindakan yang berdasar pada intensi atau niatnya (Ajzen, 2002). TPB terbagi menjadi tiga faktor motivasi yang mempengaruhi perilaku, yaitu Attitude towards behavior (Personal Attitude), Subjective Norm, Perceived Behavioral Control (Ajzen, 1991).

Intensi merupakan salah satu kumponen yang terdapat dalam diri individu yang mengacu pada keinginan untuk melakukan suatu tingkah laku tertentu, yang dapat menjadi prediktor sukses dari perilaku tersebut karena intensi dapat menghubungkan sikap dan perilaku (Ajzen dan Fishbein, 1975). Definisi lain dari Bansal et al. (2005) menyatakan bahwa intensi adalah kemungkinan subyektif individu dalam melakukan tindakan tertentu. Maka dari itu, intensi dianggap sebagai salah satu dasar utama yang harus dimiliki individu untuk melakukan sesuatu.

Kecenderungan mengambil risiko (risk-taking tendency) merupakan salah satu karakteristik dalam kepribadian individu (Robbins, 1966). Kecenderungan mengambil risiko dapat dikatakan sebagai suatu sifat yang dapat menggambarkan kecenderungan seseorang untuk mencari pengalaman baru serta berbagai macam sensasi secara kompleks dan konsisten yang menyebabkan timbulnya risiko untuk dihadapi (Zuckerman, 2000).

Locus of controlpertama kali diungkapkan oleh seorang ahli teori pembelajaran sosial bernama Rotter (1966). Menurut Rotter, locus of control merupakan cara seseorang memandang suatu peristiwa yang terjadi dalam hidupnya di mana dia mampu atau tidak mengendalikan peristiwa tersebut. Hal ini selaras dengan pernyataan Larsen dan Buss (2002), yang mendefinisikan locus of controlsebagai sebuah konsep di mana individu memiliki keyakinan akan setiap peristiwa yang terjadi dalam hidupnya.

Dalam teori motivasi yang diungkapkan McClelland, terdapat tiga macam kebutuhan yaitu need for achievement, need for power, need for affiliation. Menurut McClelland (1987), kebutuhan akan prestasi (need for achievement) adalah sebuah proses pembelajaran yang terus menerus di mana kepuasan akan didapatkan dari perjuangan yang dilakukan dan berhasil memenuhi tingkat tertinggi berjuang dan memenuhi level tertinggi dalam keahlian di bidang tertentu. Individu yang memiliki need for achievementtinggi cenderung melakukan pengambilan keputusan yang lebih berisiko dan berfokus pada tantangan-tantangan yang sulit (Griffin dan Moorhead, 2014).

Otonomi pekerjaan mengacu pada kebebasan dan kemandirian di mana individu dapat melakukan dan menentukan bagaimana cara melaksanakan tugas mereka masing-masing (Zhou dan Shalley, 2008). Selaras dengan Hackman dan Oldham (2010) yang menyatakan otonomi pekerjaan sebagai sejauh mana individu dapat dengan bebas untuk menentukan kecepatan kerjanya serta apa saja prosedur yang akan digunakan.

Tantangan pekerjaan yang ada membuat individu berada dalam sebuah kondisi yang dinamis dan penuh ketidakpastian untuk memecahkan sebuah permasalahan dan membuat pilihan dengan berbagai risiko yang ada (McCauley et al., 1994). Selain itu, tantangan pekerjaan juga didefinisikan sebagai kondisi di mana individu dihadapkan pada sebuah kegiatan baru yang menarik, namun kegiatan tersebut menuntut kemampuan dan tekad yang tinggi untuk dihadapi (De Pater et al., 2004). 
Keamanan kerja merupakan kemampuan untuk mempertahankan kesinambungan yang diinginkan dalam berbagai situasi pekerjaan yang terancam (Adebayo dan Lucky, 2012). Keamanan kerja ini merupakan faktor psikologis yang menunjukkan perasaan aman terhadap pekerjaan walaupun kondisi lingkungan ekonomi berubah-ubah (perceived impermanence) (James, 2012).

Keith Davis (2010) mengemukakan lingkungan bisnis sebagai kumpulan dari berbagai kondisi, peristiwa, dan pengaruh yang mengelilingi dan memengaruhi sebuah bisnis. Hal senada juga diungkapkan oleh Reinecke dan Schoell (1993), yaitu lingkungan untuk memulai bisnis merupakan lingkungan eksternal yang terbuka dan dapat dipengaruhi secara langsung maupun tidak langsung oleh keadaan sekitarnya.

Pendidikan kewirausahaan akan membuat individu memiliki kemampuan untuk mengarahkan bisnis dengan mengumpulkan berbagai informasi yang ada dalam menghadapi kondisi ketidakpastian yang sering dialami bisnis baru (Shephered dan Douglas, 1997). Pendidikan Kewirausahaan bukan hanya mengajarkan cara untuk menjalankan sebuah bisnis, namun juga bagaimana mengasah kemampuan berpikir kreatif (Jimah, 2011).

Gender termasuk dalam bagian dari sistem sosial, seperti status sosial, usia, dan etnis; hal tersebut merupakan faktor penting untuk menentukan peran, hak, tanggung jawab dan hubungan antara pria dan wanita (Wade dan Tavris, 2007). Gender akan terbentuk dari perilaku yang ditentukan oleh penampilan, sikap, kepribadian serta tanggung jawab (Wade dan Tavris, 2007).

Kerangka pemikirian dalam penelitian ini adalah :

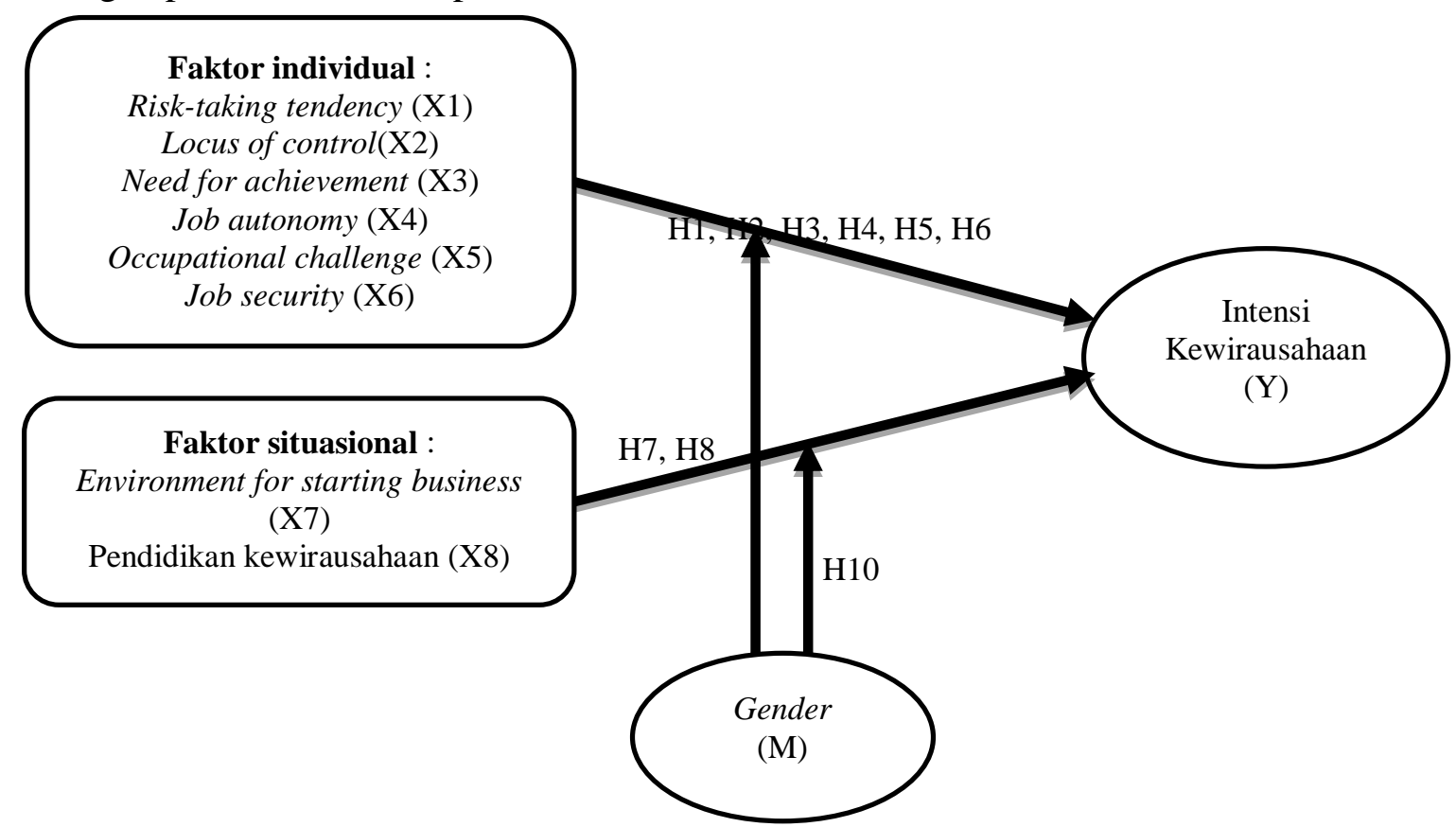

Gambar 1. Gambaran Pemikiran

Berdasarkan gambar 2.1, maka dapat dirumuskan hipotesis :

H1 : Terdapat pengaruh yang positif antara kecenderungan mengambil risiko (risk-taking tendency) terhadap intensi kewirausahaan siswa SMK di Jakarta Barat

$\mathrm{H} 2$ : Terdapat pengaruh yang positif antara locus of controlterhadap intensi kewirausahaan siswa SMK di Jakarta Barat

H3 : Terdapat pengaruh yang positif antara kebutuhan akan prestasi (need for achievement) terhadap intensi kewirausahaan siswa SMK di Jakarta Barat 
H4 : Terdapat pengaruh yang positif antara otonomi pekerjaan (job autonomy) terhadap intensi kewirausahaan siswa SMK di Jakarta Barat

H5 : Terdapat pengaruh yang positif antara tantangan pekerjaan (occupational challenge) terhadap intensi kewirausahaan siswa SMK di Jakarta Barat

H6 : Terdapat pengaruh yang negatif antara keamanan kerja (job security) terhadap intensi kewirausahaan siswa SMK di Jakarta Barat

H7 : Terdapat pengaruh yang positif antara lingkungan untuk memulai bisnis (environment for starting business) dengan intensi kewirausahaan siswa SMK di Jakarta Barat

H8 : Terdapat pengaruh yang positif antara pendidikan kewirausahaan dengan intensi kewirausahaan siswa SMK di Jakarta Barat

H9 : Faktor individual memiliki pengaruh yang lebih kuat daripada faktor situasional terhadap intensi kewirausahaan siswa SMK di Jakarta Barat

H10 : Perbedaan gender berpengaruh pada intensi kewirausahaan dan risk-taking tendency siswa SMK di Jakarta Barat

\section{METODOLOGI}

Desain penelitian yang digunakan dalam penelitian ini terbagi menjadi dua yaitu penelitian kuantitatif dan kausal. Penelitian kuantitatif berarti sebuah penelitian yang datanya diukur dalam skala numerik (angka) yang dapat dianalisis dengan menggunakan metode statistik (Sugiyono, 2013, h.13). Pengertian penelitian kausal berarti sebuah metode penelitian yang mengumpulkan data dengan tujuan untuk melihat pengaruh antar variabel-variabel yang diuji sehingga dapat menggambarkan dan menjelaskan karakteristik populasi serta suatu gejala (Sugiyono, 2012, h.59).

Dalam penelitian ini, populasinya adalah siswa/I SMK yang lokasinya berada di Jakarta Barat. Karakteristik populasi yang dipilih merupakan siswa/I sekolah SMK dengan berbagai jurusan. Mengingat terlalu banyaknya jumlah populasi yang sulit diketahui dengan pasti, maka penelitian ini menggunakan sampel yaitu hanya tiga sekolah SMK, yaitu SMK 42, SMK 45, dan SMK 60 dengan jumlah responden sebanyak 50 responden. Penelitian ini menggunakan metode non-probability sampling dan purposive sampling, di mana pengumpulan datanya menggunakan kuesioner yang disebarkan secara langsung.

Untuk melakukan pengolahan dan analisis data dalam penelitian ini digunakan software SPSS (Statistical Packages for Social Sciences). Pada tahap awal dilakukan uji validitas dan reliabilitas untuk kuesioner yang akan digunakan untuk meneliti. Kemudian untuk uji analisis data yang dilakukan yaitu, uji analisis regresi berganda, uji ANOVA, uji-F, uj-t, dan uji koefisien korelasi.

\section{HASIL UJI STATISTIK}

Pengujian validitas dan reliabilitas dalam penelitian ini dilakukan kepada 25 responden. Untuk uji validitas, nilai corrected item-total correlation $>0,3$ dari masing-masing variabel, maka dapat dinyatakan valid.Suatu kuesioner bisa dikatakan valid apablia pernyataan yang terdapat di dalamnya mampu menjelaskan sesuatu yang akan diukur melalui kuesioner tersebut. Untuk uji reliabilitas, secara keseluruhan masing-masing variabel menunjukkan hasil yang reliabel yaitu memiliki nilai Cronbach's Alpha >0,6 yang berarti indikator dapat dipercaya untuk meneliti. Jadi, suatu kuesioner dapat dinyatakan memiliki reliabilitas saat jawaban yang diberikan responden pada setiap pernyataan konsisten dan stabil dari waktu ke waktu.

Dari hasil pengumpulan data, dilakukan uji analisis regresi berganda, uji-F, uji-t, dan uji koefisien korelasi secara dua tahap. Hasil dari pengujian tersebut menyatakan nilai R square 
model 1sebesar 0,439 yang berarti sebesar 43,9\% dari variabel independen (intensi kewirausahaan) dapat dijelaskan oleh faktor individual (risk-taking tendency, locus of control, need for achievement, job autonomy, occupational challenge, dan job security), dan sisanya $56,1 \%$ dijelaskan oleh variabel lainnya.Sedangkan nilai R square pada model 2 sebesar 0,485 yang berarti sebesar 48,5\% dari variabel dependen (intensi kewirausahaan) dapat dijelaskan oleh kedelapan variabel independen yang termasuk dalam faktor individual (risk-taking tendency, locus of control, need for achievement, job autonomy, occupational challenge, dan job security) dan faktor situasional (environment for starting business dan pendidikan kewirausahaan), dan sisanya sebesar $51,5 \%$ dapat dijelaskan oleh variabel lainnya. Hal ini berarti faktor situasional (environment for starting business dan pendidikan kewirausahaan) hanya berpengaruh terhadap intensi kewirausahaan sebesar 0,046 atau 4,6\%. Hasil ujiFmenjelaskan bahwa nilai signifikansi sebesar $0,000<$ nilai $\alpha 0,05 y$ yng berarti ada satu atau lebih variabel independen yang secara bersamaan mempengaruhi variabel dependen.

Kemudian untuk menguji perbedaan gender dilakukan dengan menggunakan One-way ANOVA. Hasil menunjukkan bahwa hasil uji ANOVA dari variabel intensi kewirausahaan memiliki nilai signifikansi 0,861 dan variabel risk-taking tendency memiliki nilai signifikansi 0,159. Kedua nilai signifikansi tersebut lebih besar dari 0,05. Maka hal ini berarti tidak ada pengaruh yang signifikan antara perbedaan gender terhadap intensi kewirausahaan dan risktaking tendency.

\section{DISKUSI}

Berdasarkan hasil uji analisis regresi berganda, maka didapatkan hasil penelitian sesuai Tabel 1, yaitu :

Tabel 1. Hasil Analisis Regresi Berganda

\begin{tabular}{|c|c|c|c|}
\hline \multirow{2}{*}{ Model } & Standardized Coefficients & \multirow{2}{*}{ T } & Sig. \\
\cline { 2 - 3 } & Beta & 1,369 & 0,179 \\
\hline (Constant) & 0,902 & $-0,487$ & 0,629 \\
\hline Risk-taking Tendency & $-0,074$ & 0,294 & 0,770 \\
\hline Locus of Control & 0,037 & $-0,438$ & 0,664 \\
\hline Need for Achievement & $-0,061$ & 2,747 & 0,009 \\
\hline $\begin{array}{c}\text { Job Autonomy } \\
\text { Occupational }\end{array}$ & 0,483 & 1,203 & 0,236 \\
\hline Job Security & 0,220 & $-0,680$ & 0,500 \\
\hline $\begin{array}{c}\text { Environment for } \\
\text { Starting Business }\end{array}$ & $-0,133$ & 0,710 & 0,482 \\
\hline $\begin{array}{c}\text { Pendidikan } \\
\text { Kewirausahaan }\end{array}$ & 0,145 & 1,062 & 0,294 \\
\hline
\end{tabular}

*Sumber olahan data SPSS versi 17.0 
Untuk pengujian hipotesis menggunakan uji-t di mana besar nilai signifikansi $<0,05$ berarti hipotesis diterima. Berikut hasil pengujian hipotesis dalam penelitian ini :

\begin{tabular}{|c|l|c|}
\hline Hipotesis & \multicolumn{1}{|c|}{ Pernyataan } & Hasil \\
\hline H1 & $\begin{array}{l}\text { Terdapat pengaruh yang positif antara kecenderungan mengambil } \\
\text { risiko (risk-taking tendency) terhadap intensi kewirausahaan. }\end{array}$ & Ditolak \\
\hline H2 & $\begin{array}{l}\text { Terdapat pengaruh yang positif antara locus of controlterhadap } \\
\text { intensi kewirausahaan. }\end{array}$ & Ditolak \\
\hline H3 & $\begin{array}{l}\text { Terdapat pengaruh yang positif antara kebutuhan akan prestasi } \\
\text { (need for achievement) terhadap intensi kewirausahaan. }\end{array}$ & Ditolak \\
\hline H4 & $\begin{array}{l}\text { Terdapat pengaruh yang positif antara otonomi pekerjaan (job } \\
\text { autonomy) terhadap intensi kewirausahaan. }\end{array}$ & Diterima \\
\hline H5 & $\begin{array}{l}\text { Terdapat pengaruh yang positif antara tantangan pekerjaan } \\
\text { (occupational challenge) terhadap intensi kewirausahaan. }\end{array}$ & Ditolak \\
\hline H6 & $\begin{array}{l}\text { Terdapat pengaruh yang negatif antara keamanan kerja (job } \\
\text { security)terhadap intensi kewirausahaan. }\end{array}$ & Ditolak \\
\hline H7 & $\begin{array}{l}\text { Terdapat pengaruh yang positif antara lingkungan untuk memulai } \\
\text { bisnis (environment for starting business) dengan intensi } \\
\text { kewirausahaan. }\end{array}$ & Ditolak \\
\hline H8 & $\begin{array}{l}\text { Terdapat pengaruh yang positif antara pendidikan kewirausahaan } \\
\text { kewirausahaan dengan intensi kewirausahaaan. }\end{array}$ & Ditolak \\
\hline H9 & $\begin{array}{l}\text { Faktor individual memiliki pengaruh yang lebih kuat daripada } \\
\text { faktor situasional terhadap intensi kewirausahaan. }\end{array}$ & Diterima \\
\hline H10 & $\begin{array}{l}\text { Perbedaan gender berpengaruh pada intensi kewirausahaan dan } \\
\text { risk-taking tendency. }\end{array}$ & Ditolak \\
\hline
\end{tabular}

\section{KESIMPULAN}

Berdasarkan hasil analisis data, maka dapat diperoleh kesimpulan sebagai berikut :

1. Risk-taking tendency tidak mempengaruhi intensi kewirausahaan dan memiliki arah yang negatif terhadap intensi kewirausahaan.

2. Locus of control tidak mempengaruhi intensi kewirausahaan namun memiliki arah yang positif terhadap intensi kewirausahaan.

3. Need for achievement tidak mempengaruhi intensi kewirausahaan dan memiliki arah yang negatif terhadap intensi kewirausahaan.

4. Job autonomy mempengaruhi intensi kewirausahaan dan memiliki arah yang positif terhadap intensi kewirausahaan.

5. Occupational challenge tidak mempengaruhi intensi kewirausahaan namun memiliki arah yang positif terhadap intensi kewirausahaan.

6. Job security tidak mempengaruhi intensi kewirausahaan namun memiliki arah yang negatif terhadap intensi kewirausahaan.

7. Environment for starting business tidak mempengaruhi intensi kewirausahaan namun memiliki arah yang positif terhadap intensi kewirausahaan.

8. Pendidikan kewirausahaan tidak mempengaruhi intensi kewirausahaan namun memiliki arah yang positif terhadap intensi kewirausahaan.

9. Faktor individual memiliki pengaruh yang lebih kuat daripada faktor situasional terhadap intensi kewirausahaan. 
10. Perbedaan gender tidak berpengaruh terhadap intensi kewirausahaan dan risk-taking tendency. berikut :

Berdasarkan hasil penelitian yang telah dilakukan, maka dapat diberikan saran sebagai

1. Bagi sekolah-sekolah SMK disarankan agar meningkatkan intensi kewirausahaan siswa/I dengan cara terus memberikan pengetahuan dan pendidikan kewirausahaan. Selain itu, juga menyediakan wadah secara konkret bagi seluruh siswa/I agar bisa mengembangkan kratifitas dan keterampilan mereka di berbagai bidang, sehingga nantinya banyak dari antara siswa/I yang menjadi memiliki bisnis baru dan sukses menjadi wirausaha.

2. Bagi seluruh siswa/I SMK disarankan agar terus belajar dengan giat dan menggali potensi dalam diri masing-masing agar bisa memiliki pengetahuan, motivasi, dan keberanian untuk melakukan sesuatu yang berbeda di masa depan. Selain itu, disarankan juga untuk memanfaatkan waktu serta berbagai perkembangan teknologi yang ada sebagai peluang untuk berwirausaha sehingga kesempatan yang ada tidak sia-sia begitu saja.

3. Bagi peneliti selanjutnya disarankan agar mengambil jumlah sampel yang lebih banyak lagi agar hasil yang didapatkan bisa lebih baik dan digeneralisasi.

\section{DAFTAR PUSTAKA}

Abdi, H. (2019, March 25). Ini 6 Cara Mengatasi Pengangguran, dari Pendidikan hingga Transmigrasi. Retrieved from CITIZEN6: Liputan6 Web site: http://liputan6.com

Adebayo, O., \& Lucky, O. (2012). Enterpreneurship Development And National Job Security. Proceedings of the LASPOTECH SM National Conference on National Job Security Main Auditorium. Lagos, Nigeria: isolo Campus.

Adharsyah, T. (2019, August 17). 74 Tahun RI Belum Merdeka dari Pengangguran \& Kemiskinan. Retrieved from News : CNBC Indonesia: http://cnbcindonesia.com

Ajzen, I. (1991). The Theory of Planned Behavior. Organizational Behavior and Human Decision Processes, 50, 179-211.

. (2002). Perceived Behavioral Control, Self-Efficacy, Locus of Control, and The Theory of Planned Behavior. Organizational Behavior and Human Decission Processes, 50, 179-211.

Badan Pusat Statistik. (2019, May 6). Februari 2019: Tingkat Pengangguran Terbuka (TPT) sebesar 5,01 persen. Retrieved from Badan Pusat Statistik Web Site: http://www.bps.go.id

Badan Pusat Statistik. (2019, July 15). Persentase penduduk miskin Maret 2019 sebesar 9,41 persen. Retrieved from Badan Pusat Statistik Web Site: http://www.bps.go.id

Bansal et al. (2005). Migrating to New Service Providers: Toward Unifyng Framework of Customer's Switching Intention. Journal of The Academy Marketing Science, 2, 200218.

Budner, S. (1962). Intolerance of Ambiguity as a Personality Variable. Journal of Personality, 30, 29-50.

Davidsson, P., \& Henrekson, M. (2002). Determinants oftheprevalenceofstart-ups andhighgrowth firms. Small Business Economics, 19(2), 81-104.

Davis, Keith. 2010. Organizational Behavior - Human Behavior at Work $13^{\text {th }}$ Edition. New Delhi: Mcgraw Hill Company. 
De Pater, I., Judge, T., \& Van Vianen, A. (2004). Emotional Stability, Core self-evaluations, and Job Outcomes: A review of the evidence and agenda for future research. Human Performance, 17(3), 325-346.

Diaz-Garcia, M., \& Jimenez-Moreno, J. (2010). Entrepreneurial intention: the role of gender. International Entrepreneurship and Management Journal, 6(3), 261-283.

Fishbein, M., \& Ajzen, I. (1975). Belief, Attitude, Intention, and Behavior: An Introduction to Theory and Research, Reading. MA: Addison-Wesley.

Gelard, P., \& Saleh, K. (2010). Impact of some contextual factors on entrepreneurial intention of university students. African Journal of Business Management, 5(26), 10707-10717.

Griffin, R., \& Moorhead, G. (2014). "Organizational Behavior: Managing People and Organizations" (Eleventh ed.). USA: South Western.

James, G. (2012). How to achieve true job security. Retrieved from http://www.inc.com/geoffrey-james/how-to-achieve-true-job-security.html

Jimah, M., \& Unuigbokhai, O. (2011). ENTERPRENEURSHIP EDUCATION: A TOOL FOR SUSTAINABLE DEVELOPMENT IN NIGERIA. Entrepreneurship Education.

Keat, O., Selvarajah, C., \& Meyer, D. (2011). Inclination towards entrepreneurship among university students: an empirical study of Malaysian university students. International Journal of Business and Social Science, 2(4), 206-220.

Krueger, N. (1993). The impact of prior entrepreneurial exposure on perceptions of new venture feasibility and desirability. Entrepreneurship Theory and Practice, 12, 5-23.

Larsen, R., \& Buss, D. (2005). Personality psychology: domains of knowledge. Boston: McGraw-Hill.

Linan, F., Rodriguez-Cohard, \& Rueda-Cantuche, J. (2011). Factors affecting entrepreneurial intention levels: a role for education. International Entrepreneurship Management Journal, 7(2), 195-218.

Mazzarol, T., Volerey, T., Doss, N., \& Thein, V. (1999). Factors influencing small business start-ups. International Journal of Entrepreneurial Behavior \& Research, 5(2), 48-63.

McCauley, C., Rudermen, M., Ohlott, P., \& Morrow, J. (1994). Assessing the Developmental Components of Managerial Jobs. Journal of Applied Psychology, 79(4), 544-560.

McClelland, D. (1965). Achievement and entrepreneurship: a longitudinal study. Journal of Personality and Social Psychology, 1(4), 389-392.

Oldham, G., \& Hackman, J. (2010). Not what it was and not what it will be: The future of job design research. Journal of Organizational Behavior, 31(2-3), 463-479.

Probst, T. (2006). Job Security. In J. Greenhaus, \& G. Callanan, Encyclopedia of Career Development (pp. 442-445). Thousand Oaks, CA: Sage Publications.

Robbins, S. (1996). Perilaku Organisasi, Konsep, Kontroversi, dan Aplikasi (6th ed.). (H. Pujaatmaka, Trans.) Jakarta: PT Bhuana Ilmu Populer.

Rotter, J. (1966). Generalized expectancies for internal versus external control of reinforcement. Psychological Monographs, 80(1), 1-28.

Schere, J. (1982). Tolerance of ambiguity as a discriminating variable between entrepreneurs and managers. Academy of Management Proceeding, 404-408.

Schoell, W., Reinecke, J., \& Dessler, G. (1993). Introduction to Business. Boston: Allyn and Bacon.

Sesen, H. (2013). Personality or environment? A comprehensive study on the entrepreneurial intentions of university students. Education+Training, 55(7), 624-640.

Shane, S., Locke, E., \& Collins, C. (2012). Entrepreneurial Motivation. Human Resource Management Review, 13(2), 257-279.

Shephered, D., \& Douglas, E. (1997). Is management education developing or killing the entrepreneurial spirit? Paper presented at the 42nd International Council for Small Business Conference. Sanfrancisco, CA. 
Stewart, W., \& Roth, P. (2001). Risk propensity differences between entrepreneurs and managers: a meta-analytic review. Journal of Applied Psychology, 86(1), 145-153. , ., Watson, W., Carland, J., \& Carland, J. (1999). A proclivity for entrepreneurship: a comparison of entrepreneurs, small business owners, and corporate managers. Journal of Business Venturing, 14(2), 105-118.

Sugiyono. (2012). Metode Penelitian Kuantitatif Kualitatif dan $R \& D$. Bandung: Alfabeta. . (2013). Metode Penelitian Pendidikan Pendekatan Kuantitatif, Kualitatif, dan $R \& D$. Bandung: Alfabeta.

Timmons, J., \& Spinelli, S. (2009). New Venture Creation :Entrepreneurship for the 21st Century. Mc.Graw-Hill.

Wade, C., \& Tavris, C. (2007). Psychology (9th ed.). Jakarta: Erlangga.

Walter, S., \& Heinrichs, S. (2015). Who becomes an entrepreneur? A 30-years-review of individual level research. Journal of Small Business and Enterprise Development, 22(2), 225-248.

Wang, W., Wei, M., \& John, K. (2011). Determinants of entrepreneurial intention among college students in China and USA. Journal of Global Entrepreneurial Research, $1(1), 35-44$.

Wilson, F., Kickul, J., \& Marlino, D. (2007). Gender, entrepreneurial self-efficacy, and entrepreneurial career intentions: implications for entrepreneurship education. Entrepreneurship Theory \& Practice, 33(3), 387-406.

Zhou, J., \& Shalley, C. (2008). The Oxford Handbook of Creativity, Innovation, and Entrepreneurship. Oxford: Oxford University Press.

Zuckerman, M., \& Kuhlman, D. (2000). Personality and Risk Taking : Common Biosocial Factor. Journal of Personality, 68(6). 